\title{
Inhibition of L-Kynurenine 3-Hydroxylase from Saccharomyces carlsbergensis by $\alpha$-Keto Acid Derivatives of Branched Chain Amino Acids
}

\author{
Mariko ShIN, Keiji SANo, and Chisae UMEZAWA ${ }^{1}$ \\ School of Pharmacy, Kobe-Gakuin University, \\ Tarumi-ku, Kobe 673, Japan
}

(Received July 10, 1981)

\begin{abstract}
Summary L-Kynurenine 3-hydroxylase [EC 1.14.1.2] was partially purified from the mitochondrial outer membrane fraction of Saccharomyces carlsbergensis by Sephadex G-200 gel chromatography, and the effects of leucine and its related compounds on the enzyme were investigated.

$\alpha$-Keto acid derivatives of the three branched chain amino acids were found inhibitory to the partially purified kynurenine 3-hydroxylase, but branched chain amino acids were without effect. $\alpha$-Ketoisocaproate (KIC), a keto acid analogue of L-leucine, inhibited kynurenine 3-hydroxylase noncompetitively with apparent $K_{\mathrm{i}}$ values of 4.2 and $8.3 \mathrm{~mm}$ for kynurenine and NADPH respectively. $\alpha$-Ketoglutarate and pyruvate were mixed-type inhibitors of the enzyme.

KIC production by $S$. carlsbergensis grown in medium containing no leucine was negligible, while that in leucine-supplemented medium increased in proportion to the amount of L-leucine incorporated into cells. From the results, it was proposed that KIC produced from leucine lowered synthesis of NAD from tryptophan by inhibiting L-kynurenine 3hydroxylase, a possible rate-limiting enzyme in the tryptophan-NAD pathway in Saccharomyces carlsbergensis.
\end{abstract}

Key Words Saccharomyces carlsbergensis, tryptophan-NAD pathway, Ltryptophan and/or L-leucine, L-kynurenine 3-hydroxylase, $\alpha$-ketoisocaproate, $\alpha$-keto acids

In the preceding paper(1), the authors reported that tryptophan-dependent niacin synthesis in $S$. carlsbergensis was repressed in the presence of leucine. Quinolinate phosphoribosyltransferase [EC 2.4.2.19] activity was not lowered in the cells grown in the medium supplemented with leucine(1). Total niacin synthesis

\footnotetext{
${ }^{1}$ 新 真理子, 佐野圭二, 梅澤智佐江
} 
from 3-hydroxyanthranilate and cellular incorporation of tryptophan were not affected by leucine (1). The results suggested that leucine might inhibit kynurenine 3-hydroxylase, an another rate-limiting step in the tryptophan-NAD pathway.

L-Kynurenine 3-hydroxylase has been reported to be localized in the mitochondrial outer membrane in Saccharomyces (2). Purification of the enzyme, however, has not been accomplished yet. The authors, therefore, attempted to purify kynurenine 3-hydroxylase from aerobically grown $S$. carlsbergensis by following the method used for purification of the rat liver enzyme (3) with slight modifications and investigated the effect of leucine and its related compounds on the partially purified enzyme.

\section{EXPERIMENTAL}

Materials. Digitonin and polyethylene glycol 20,000 were purchased from Wako Pure Chemical Industries, Ltd. FAD, dithiothreitol, L-kynurenine, $\alpha$ ketoglutarate, oxaloacetic acid and branched chain amino acids were obtained from Nakarai Chemicals, Ltd., Zymolyase-5000 from Kirin Brewery Co., Ltd., Sephadex G-200 from Pharmacia Fine Chemicals and NADPH from Oriental Yeast Co., Ltd. Branched chain $\alpha$-keto acids and acetoacetate were purchased from Sigma Chemical Co.

Preparation of the mitochondrial outer membrane. To obtain a large quantity of mitochondria, S. carlsbergensis was cultured in YPG medium (4) in a jar fermentor at $30^{\circ} \mathrm{C}$ with air supplied at a rate of 7.5 liters per min. After $20 \mathrm{hr}$ of incubation, cells were harvested, washed with saline and lyophilized. The lyophilized cells were treated with Zymolyase-5000 in the presence of $10 \mathrm{~mm} 2$-mercaptoethanol at $\mathrm{pH}$ 7.5(5). DNase was also added to reduce viscosity and to make the following manipulations easier. All operations of preparation and subsequent fractionation of mitochondria were carried out at $0-4^{\circ} \mathrm{C}$. The protoplasts obtained by the Zymolyase treatment were blended in the presence of $1.3 \mathrm{M}$ sorbitol, $0.1 \mathrm{~mm}$ EDTA and $0.01 \mathrm{M}$ Tris- $\mathrm{HCl}$ buffer ( $\mathrm{pH} 7.5$ ). The blended cells were centrifuged at 2,500 $\times g$ for $5 \mathrm{~min}$. The precipitate was blended and centrifuged again. The combined supernatant was centrifuged at $20,000 \times g$ for $30 \mathrm{~min}$. The precipitate obtained was used as the mitochondrial fraction.

The mitochondrial outer membrane fraction was prepared according to the method of Okamoto and Hayaishi(3) using digitonin. The diluted suspension of mitochondria in the digitonin solution was centrifuged at $12,000 \times g$ for $12 \mathrm{~min}$. The pellet was resuspended in the mannitol solution and again centrifuged at $12,000 \times g$ for $12 \mathrm{~min}$. The resultant pellet contained the inner membrane and matrix. The pooled supernatant was centrifuged at $105,000 \times g$ for $90 \mathrm{~min}$, the pellet containing the outer membrane.

Solubilization and partial purification of L-kynurenine 3-hydroxylase from the mitochondrial outer membrane fraction. The mitochondrial outer membrane fraction was suspended in the mannitol solution and the $1 \%$ digitonin solution was added in 
the presence of $20 \mu \mathrm{M}$ FAD and $5 \mathrm{~mm}$ dithiothreitol (DTT). The suspension was stirred for $3 \mathrm{hr}$ in an ice bath and centrifuged at $105,000 \times g$ for $90 \mathrm{~min}$. The resultant supernatant was placed in Visking cellulose tubing coverd with polyethylene glycol 20,000 powder at $4^{\circ} \mathrm{C}$ for $5 \mathrm{hr}$. The concentrated supernatant was used as crude enzyme, which was applied to a column $(1.2 \times 42 \mathrm{~cm})$ of Sephadex G200 equilibrated with a buffer $(50 \mathrm{~mm}$ Tris- $\mathrm{HCl}$ buffer $(\mathrm{pH} 8.0)$ containing $20 \mu \mathrm{M}$ FAD and $5 \mathrm{~mm}$ DTT). The enzyme was eluted with the same buffer at a flow rate of 1 drop per $13 \mathrm{sec}$ and fractions of $600 \mu \mathrm{l}$ were collected. Proteins were monitored by absorbance at $280 \mathrm{~nm}$. Digitonin was determined as glucose by the phenol- $\mathrm{H}_{2} \mathrm{SO}_{4}$ method (6).

Assay of L-kynurenine 3-hydroxylase activity (7). The assay mixture contained, in a final volume of $1 \mathrm{ml}$, the following compounds in $\mu$ mol: L-kynurenine, $1 \mu \mathrm{mol}$; NADPH, $0.5 \mu \mathrm{mol}$; KCN, $10 \mu \mathrm{mol}$; PCMB, $40 \mu \mathrm{mol}$; Tris- $\mathrm{HCl}$ buffer, $\mathrm{pH} 8.0,0.1$ $\mathrm{mmol}$ and appropriate amounts of the enzyme preparation. The reaction was started by adding the enzyme, and the incubation was carried out at $30^{\circ} \mathrm{C}$ with shaking. The reaction was stopped by addition of $0.5 \mathrm{ml}$ of a $0.2 \mathrm{M}$ solution of $\mathrm{K}_{3} \mathrm{Fe}(\mathrm{CN})_{6}$ in $1 \mathrm{M}$ phosphate buffer ( $\mathrm{pH}$ 6.8). The xanthommatine formed and the excess ferricyanide were reduced by adding $100 \mathrm{mg}$ of ascorbic acid. The dihydroxanthommatine was immediately extracted with $1.5 \mathrm{ml}$ of butanol- $\mathrm{HCl}$ $(12 \mathrm{ml}$ butanol $+1 \mathrm{ml}$ conc. $\mathrm{HCl})$, and the extinction of the organic phase was read at $492 \mathrm{~nm}$. One unit of enzyme was defined as the amount which catalyzed the formation of $1 \mathrm{nmol}$ of 3-hydroxykynurenine per min at $30^{\circ} \mathrm{C}$. Protein was determined by the method of Lowry et al.(8) with bovine serum albumin as a protein standard.

Procedure for measurement of $\alpha$-ketoisocaproate. S. carlsbergensis was cultivated with either leucine alone or leucine plus tryptophan in apple-shaped flasks agitated on a shaker at $37^{\circ} \mathrm{C}$. At certain time intervals cells were centrifuged and $\alpha$ ketoisocaproate formed was analyzed according to Ichihara and Koyama (9) with the following modifications.

To $4 \mathrm{ml}$ of the culture broth or the culture filtrate, $0.5 \mathrm{ml}$ of the $90 \%$ TCA solution was added. The mixture was stood at $0^{\circ} \mathrm{C}$ for $30 \mathrm{~min}$, centrifuged, and the clear supernatant was used as a sample. One $\mathrm{ml}$ of Tris-ketoglutarate buffer $(0.02 \mathrm{M}$ $\alpha$-ketoglutarate, $0.2 \mathrm{M}$ Tris- $\mathrm{HCl}(\mathrm{pH} \mathrm{8.6)}), 2 \mathrm{ml}$ of a sample (the TCA extract) and $1 \mathrm{ml}$ of the dinitrophenylhydrazine solution (2,4-dinitrophenylhydrazine $300 \mathrm{mg}$, $\mathrm{HCl} 17 \mathrm{ml}$, water $83 \mathrm{ml}$ ) were mixed and stood at room temperature for exactly 10 min. The mixture was extracted by shaking vigorously with $5 \mathrm{ml}$ of cyclohexane for $20 \mathrm{sec}$ and centrifuged. Four $\mathrm{ml}$ of the cyclohexane phase was extracted with $1.5 \mathrm{ml}$ of the $10 \% \mathrm{Na}_{2} \mathrm{CO}_{3}$ solution and $2 \mathrm{ml}$ of $1 \mathrm{~N} \mathrm{NaOH}$ was added to $1 \mathrm{ml}$ of the $\mathrm{Na}_{2} \mathrm{CO}_{3}$ phase. After standing for 5 to $20 \mathrm{~min}$, the extinction of the $\mathrm{Na}_{2} \mathrm{CO}_{3}$ phase was read at $440 \mathrm{~nm}$. 


\section{RESULTS}

Stability of kynurenine 3-hydroxylase in intact mitochondria

Mitochondrial suspensions in $100 \mathrm{~mm}$ buffers of various $\mathrm{pH}$ were stood for $2 \mathrm{hr}$ at $30^{\circ} \mathrm{C}$, the residual enzyme activities being shown in Fig. 1. The enzyme was fairly stable at a pH between 5 and 10, while at either a $\mathrm{pH}$ lower than 5 or at a $\mathrm{pH}$ higher than 10 the enzyme was unstable. All operations of preparation and subsequent fractionation of mitochondria were, therefore, carried out at $\mathrm{pH} 8$.

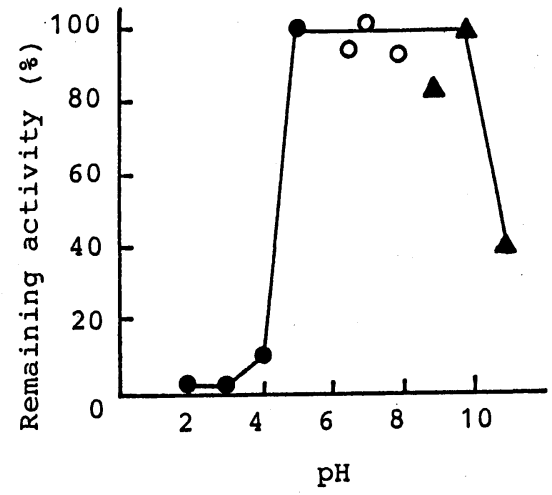

Fig. 1. pH Stability of L-kynurenine 3-hydroxylase in intact mitochondria. $\bullet$, acetate buffer; $\bigcirc$, phosphate buffer; $\boldsymbol{\Delta}$, borate buffer.

Table 1. Effect of various compounds on L-kynurenine 3-hydroxylase in intact mitochondria.

Intact mitochondria (1.72 $\mathrm{mg}$ protein/assay mixture) were used as an enzyme source. The kynurenine 3-hydroxylase activity was measured as described under EXPERIMENTAL.

\begin{tabular}{|c|c|c|c|}
\hline \multirow[b]{2}{*}{ Compound added } & \multirow{2}{*}{$\begin{array}{l}\text { Conc. } \\
\text { (mM) }\end{array}$} & \multicolumn{2}{|c|}{ L-Kynurenine 3-hydroxylase } \\
\hline & & $\begin{array}{l}\text { Specific activity } \\
\text { (unit/mg protein) }\end{array}$ & $\begin{array}{c}\text { Relative activity } \\
(\%)\end{array}$ \\
\hline None & - & 0.566 & 100 \\
\hline L-Leucine & 20 & 0.596 & 105 \\
\hline L-Isoleucine & 20 & 0.648 & 114 \\
\hline L-Valine & 20 & 0.660 & 117 \\
\hline$\alpha$-Ketoisocaproate & 19.4 & 0.056 & 9.9 \\
\hline DL- $\alpha$-Keto- $\beta$-methyl- $n$-valerate & 38.8 & 0.086 & 15.2 \\
\hline$\alpha$-Ketoisovalerate & 19.4 & 0.019 & 3.4 \\
\hline Acetoacetate & 20 & 0.596 & 105 \\
\hline$\alpha$-Ketoglutarate & 20 & 0.283 & 50 \\
\hline Pyruvate & 20 & 0.667 & 118 \\
\hline
\end{tabular}


Effect of various compounds on kynurenine 3-hydroxylase in intact mitochondria

Branched chain amino acids, their keto acid analogues and other keto acids were tested for their effects on mitochondrial kynurenine 3-hydroxylase (Table 1). Among the compounds tested, branched chain $\alpha$-keto acids inhibited kynurenine 3hydroxylase specifically. $\alpha$-Ketoglutarate was weakly inhibitory to this enzyme. Branched chain $\alpha$-keto acids are known to be metabolized by mitochondria in rat liver(10), and therefore the possibility could not be excluded that the further metabolites of the branched chain $\alpha$-keto acids might be responsible for the inhibition. To determine the mechanism of inhibition, purification of kynurenine 3hydroxylase was attempted.

\section{Stabilization of solubilized enzyme}

Kynurenine 3-hydroxylase activity in the outer mitochondrial membrane fraction was found to be stable over a period of at least 15 days when stored at $-20^{\circ} \mathrm{C}$. In contrast, the solubilized enzyme was unstable, losing nearly $80 \%$ of the total activity when stored for $20 \mathrm{hr}$ at $-20^{\circ} \mathrm{C}$. The stabilization of the solubilized rat liver enzyme activity was achieved by the addition of glycerol and DTT (3) or FAD, DTT and L-kynurenine (11). In Table 2 the relative enzyme activities after adding several stabilizing agents are shown on the activity of the non-solubilized enzyme being defined as 100 . A combination of $5 \mathrm{~mm}$ DTT and $20 \mu \mathrm{M}$ FAD was found to be relatively effective. Both DTT and FAD activated non-solubilized kynurenine 3hydroxylase.

Partial purification of kynurenine 3-hydroxylase from mitochondrial outer membrane Kynurenine 3-hydroxylase is known to be exclusively bound to the outer

Table 2. Effect of DTT and/or FAD on L-kynurenine 3-hydroxylase.

\begin{tabular}{lccc}
\hline \multirow{2}{*}{ Addition } & \multicolumn{2}{c}{ Relative activity (\%) } & Solubilized \\
\cline { 2 - 3 } & $\begin{array}{c}\text { Non-solubilized } \\
\text { Enz. }^{\text {a }}\end{array}$ & $\begin{array}{c}\text { Solubilized } \\
\text { Enz. }\end{array}$ & Non-solubilized \\
& 100 & 25 & \\
\hline None & 193 & 57 & 25 \\
DTT $5 \mathrm{mM}$ & 197 & 79 & 30 \\
DTT $20 \mathrm{mM}$ & 212 & 73 & 40 \\
FAD $5 \mu \mathrm{M}$ & 235 & 94 & 34 \\
FAD $10 \mu \mathrm{M}$ & 214 & 94 & 40 \\
FAD $20 \mu \mathrm{M}$ & 226 & 148 & 44 \\
DTT $5 \mathrm{mM}+$ FAD $20 \mu \mathrm{M}$ & & 66 \\
\hline
\end{tabular}

${ }^{a}$ The mitochondrial outer membrane fraction $(0.90 \mathrm{mg}$ protein/assay mixture $)$ was used as a non-solubilized enzyme. ${ }^{\mathrm{b}}$ The mitochondrial outer membrane fraction treated with the $1 \%$ digitonin solution for $3 \mathrm{hr}$ in an ice bath $(0.82 \mathrm{mg}$ protein/assay mixture) was used as a solubilized enzyme.

Vol. 28, No. 3, 1982 


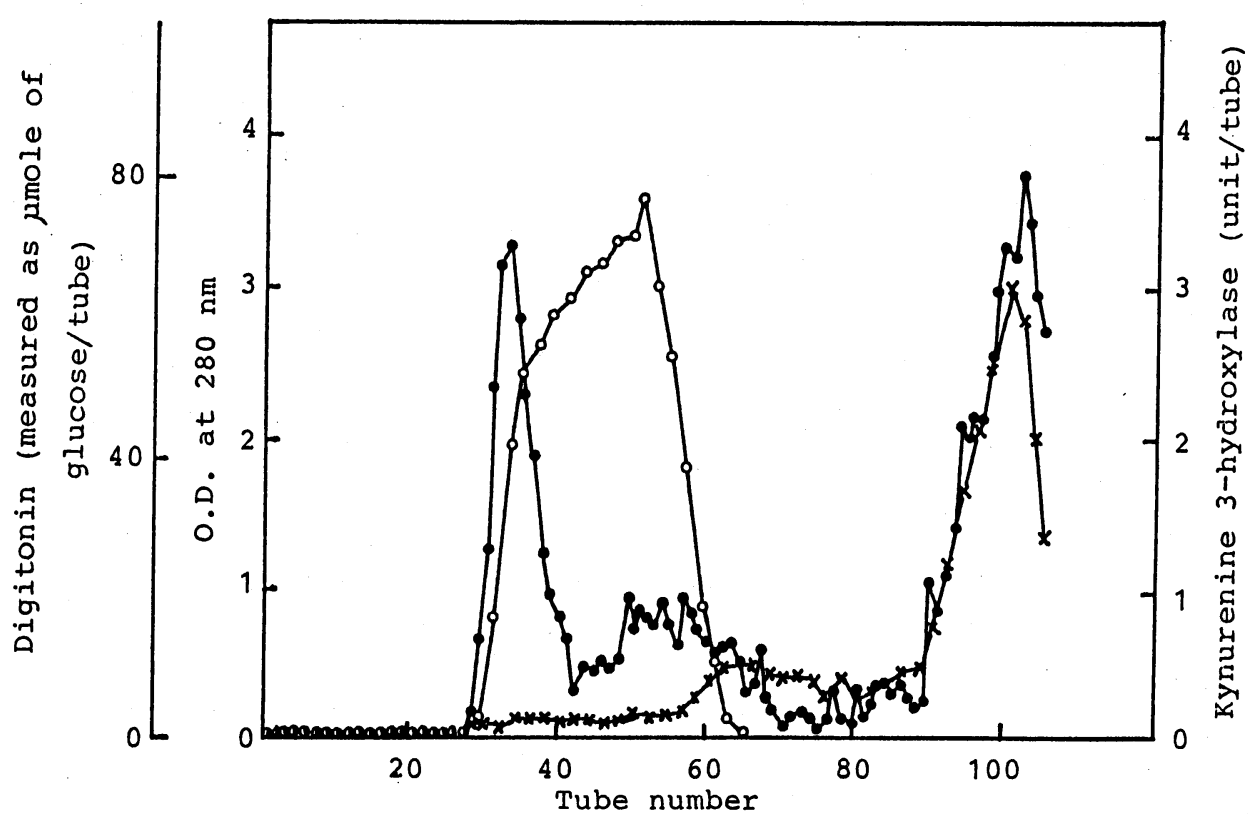

Fig. 2. Sephadex G-200 chromatogram of the digitonized mitochondrial outer membrane. $-A_{280} ; \mathrm{O}$, L-kynurenine 3-hydroxylase activity; $\times$, digitonin aggregate measured using the phenol- $\mathrm{H}_{2} \mathrm{SO}_{4}$ method.

mitochondrial membrane in yeast(2). To release the enzyme from the outer mitochondrial membrane, treatment with digitonin or Triton X-100 was tested. As the latter compound was found to disturb the measurement of kynurenine 3hydroxylase activity, digitonin was used in the presence of $20 \mu \mathrm{M}$ FAD and $5 \mathrm{~mm}$ DTT to release the enzyme. The digitonized outer membrane fraction was centrifuged at $105,000 \times g$ for $90 \mathrm{~min}$. The supernatant was concentrated and applied to a column of Sephadex G-200 equilibrated with Tris- $\mathrm{HCl}$ buffer. The elution pattern is shown in Fig. 2.

Tube numbers 31 through 35 (fraction I), 36 through 40 (fraction II), 41 through 59 (fraction III) and 60 through 63 (fraction IV) were combined. Specific activities of kynurenine 3-hydroxylase in each of the combined fractions were 1.2 (fraction I), 1.9 (fraction II), 4.0 (fraction III) and 0.4 (fraction IV) unit per mg protein respectively.

As fraction III had the highest specific activity and was devoid of digitonin aggregates, it was used as a partially purified enzyme. It was unable to maintain full activity of kynurenine 3-hydroxylase even in the presence of stabilizing agents. The specific activity of this enzyme, therefore, did not reflect the exact degree of purification. As shown in Table 3, increase in the specific activity could not be achieved by gel filtration with Sephadex G-200. The partially purified enzyme was used in the following experiments immediately after its preparation. 
Table 3. Purification of L-kynurenine 3-hydroxylase from S. carlsbergensis.

\begin{tabular}{lccc}
\hline Fraction & Total protein & \multicolumn{2}{c}{ L-Kynurenine 3-hydroxylase } \\
\cline { 3 - 4 } & $(\mathrm{mg})$ & $\begin{array}{c}\text { Total activity } \\
\text { (unit) }\end{array}$ & $\begin{array}{c}\text { Specific activity } \\
\text { (unit/mg protein) }\end{array}$ \\
\hline Mitochondria & 6,250 & 12,700 & 2.0 \\
Outer membrane & 877 & 2,180 & 2.5 \\
Solubilized Enz. & 400 & 1,690 & 4.2 \\
Sephadex G-200 & 48 & 193 & 4.0 \\
(Fraction III) & & & \\
\hline
\end{tabular}

Table 4. Effect of various compounds on partially purified L-kynurenine 3hydroxylase.

Partially purified enzyme (Fraction III after Sephadex G-200 filtration; $0.139 \mathrm{mg}$ protein/assay mixture) was used as an enzyme source.

\begin{tabular}{|c|c|c|c|}
\hline \multirow[b]{2}{*}{ Compound added } & \multirow{2}{*}{$\begin{array}{l}\text { Conc. } \\
(\mathrm{mM})\end{array}$} & \multicolumn{2}{|c|}{ L-Kynurenine 3-hydroxylase } \\
\hline & & $\begin{array}{l}\text { Specific activity } \\
\text { (unit/mg protein) }\end{array}$ & $\begin{array}{c}\text { Relative activity } \\
(\%)\end{array}$ \\
\hline None & - & 2.53 & 100 \\
\hline L-Leucine & 20 & 2.88 & 114 \\
\hline L-Isoleucine & 20 & 2.94 & 116 \\
\hline L-Valine & 20 & 3.03 & 120 \\
\hline$\alpha$-Ketoisocaproate & 17.0 & 0.326 & 12.9 \\
\hline DL- $\alpha$-Keto- $\beta$-methyl- $n$-valerate & 28.8 & 0.021 & 0.8 \\
\hline$\alpha$-Ketoisovalerate & 15.5 & 0.029 & 1.2 \\
\hline Acetoacetate & 20 & 2.19 & 86.6 \\
\hline$\alpha$-Ketoglutarate & 20 & 0.041 & 1.6 \\
\hline Pyruvate & 20 & 0.049 & 1.9 \\
\hline
\end{tabular}

Effect of various compounds on partially purified kynurenine 3-hydroxylase

Three branched chain $\alpha$-keto acids, but not branched chain amino acids, were inhibitory to partially purified kynurenine 3-hydroxylase (Table 4). Pyruvate had no inhibitory effect on the intact mitochondrial enzyme, while both $\alpha$-ketoglutarate and pyruvate were inhibitory to the partially purified enzyme to the same extent as branched chain $\alpha$-keto acids (Tables 1 and 4).

The $K_{\mathrm{m}}$ 's calculated from reciprocal plots of reaction velocity versus substrate concentration are $1.47 \times 10^{-4} \mathrm{M}$ for kynurenine and $2.0 \times 10^{-4} \mathrm{M}$ for NADPH (Fig. 3). KIC was a noncompetitive inhibitor for kynurenine 3-hydroxylase and $K_{\mathrm{i}}$ 's determined from Dixon plots are $4.2 \mathrm{~mm}$ for kynurenine and $8.3 \mathrm{~mm}$ for NADPH (Fig. 4). $\alpha$-Ketoglutarate and pyruvate were mixed-type inhibitors of kynurenine 3-

Vol. 28, No. 3, 1982 

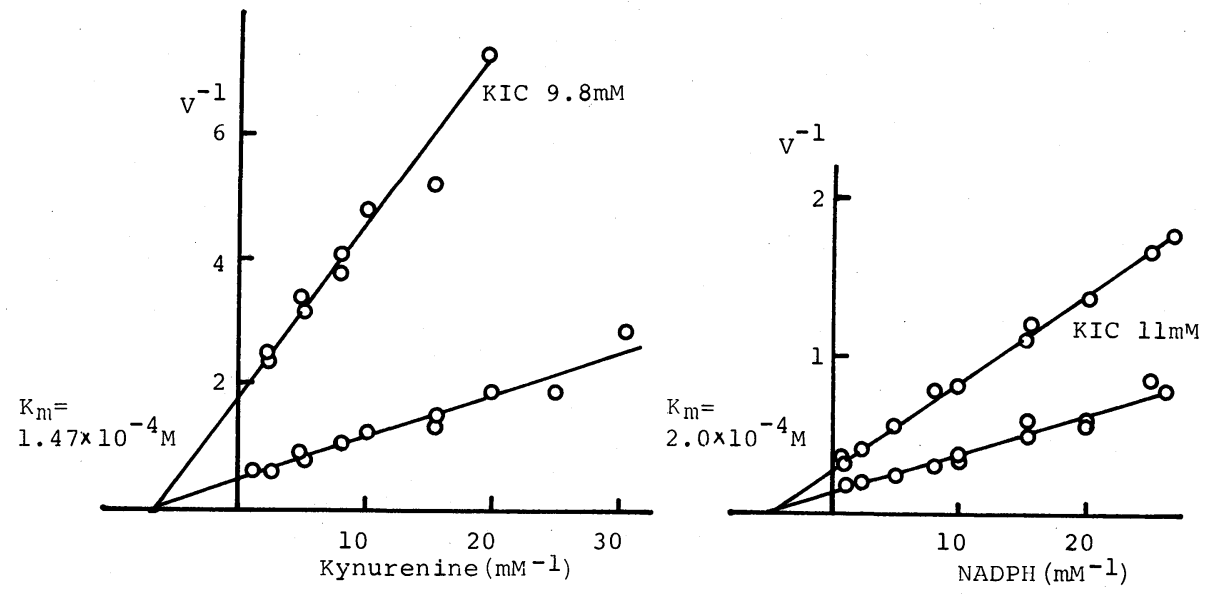

Fig. 3. Lineweaver-Burk plots relating L-kynurenine 3-hydroxylase activity to concentration of substrates.
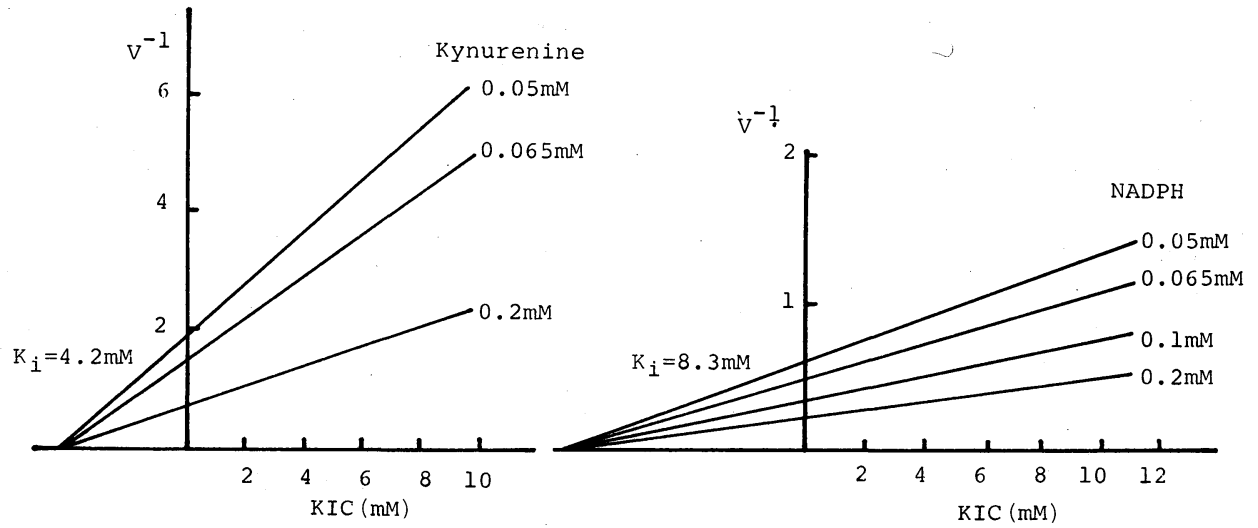

Fig. 4. Dixon plots to determine the $K_{\mathrm{i}}$ for KIC of L-kynurenine 3-hydroxylase.

hydroxylase.

\section{Production of $\alpha$-ketoisocaproate in the medium}

$\mathrm{KIC}$ was produced in a detectable amount only when leucine was added to the medium. Most of the KIC determined was present in the supernatant (Fig. 5).

\section{DISCUSSION}

Biosynthesis of NAD from tryptophan in higher animals has been reported to be controlled by the activity of $\alpha$-amino $\beta$-carboxymuconate $\varepsilon$-semialdehyde decarboxylase [EC 4.1.1.45]. The higher the activity of this enzyme, the more 


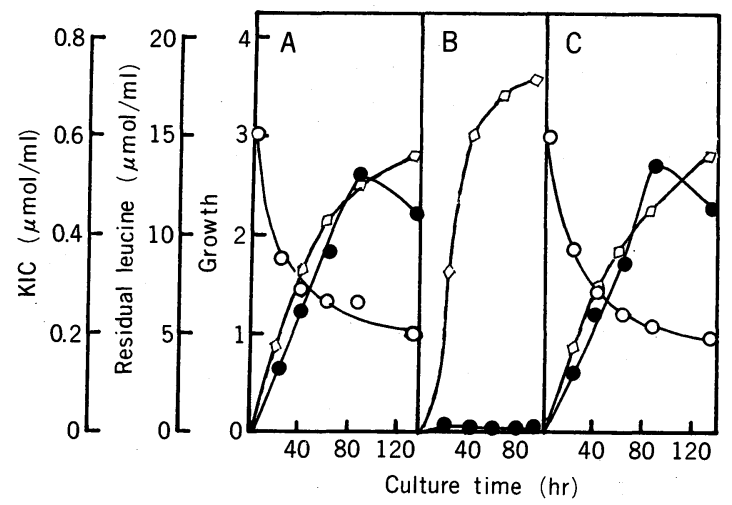

Fig. 5. Disappearance of added leucine and appearance of KIC in the culture filtrate. (A) leucine-supplemented medium, (B) tryptophan-supplemented medium, (C) tryptophan- and leucine-supplemented medium. $\diamond$, growth $\left(A_{610}\right) ; \bigcirc$, residual leucine; $\bullet$, KIC formed.

tryptophan is completely degraded and less NAD formed(12). In Saccharomyces the activity of this enzyme could not be detected and there might exist a control mechanism different from that in higher animals.

Another major branch point in the tryptophan-NAD pathway is kynurenine, which can act as a substrate for either kynureninase [EC 3.7.1.3], L-kynurenine 3hydroxylase or kynurenine aminotransferase [EC 2.6.1.7]. A decrease in NAD levels in the liver of rats given thyroxine was reported to be due to a decrease in kynurenine 3-hydroxylase activity, which suggested that this enzyme also played an important role in controlling the tryptophan-NAD pathway(13). In our present study, kynurenine 3-hydroxylase in intact yeast mitochondria was found to be inhibited by $\alpha$-keto acid derivatives of branched chain amino acids. The partially purified enzyme was inhibited not only by $\alpha$-keto acid analogues of branched chain amino acids but also by pyruvate and $\alpha$-ketoglutarate. Pyruvate and $\alpha$-ketoglutarate are expected to be metabolized rapidly by pyruvate dehydrogenase and enzymes of the tricarboxylic acid cycle in intact mitochondria. This was probably why pyruvate was not inhibitory and $\alpha$-ketoglutarate was only weakly inhibitory to this enzyme when intact mitochondria were used as an enzyme source.

$\alpha$-Keto acids of branched chain amino acids have been subjected to metabolism by mitochondrial enzymes in rat liver (14). Incorporation of KIC into the mitochondria of rat liver has been reported to be carrier mediated and not to occur by passive diffusion even at elevated concentrations (15). In our experiment, a large amount of KIC was released into the medium when Saccharomyces was cultivated with leucine, which suggested that a similar control mechanism was operating in the transport of $\mathrm{KIC}$ into yeast mitochondria. The disappearance of KIC was very slow compared to that of pyruvate, so that KIC might show a strong apparent inhibition.

The highest concentration of KIC accumulated in the medium was $0.5 \mathrm{~mm}$, as 
shown in Fig. 5. On the other hand, the $50 \%$ inhibitory concentration of KIC on kynurenine 3-hydroxylase in the intact mitochondria was about $5 \mathrm{~mm}$. A possibility, however, that the concentration of KIC in the region of mitochondria where kynurenine 3-hydroxylase is localized might be raised to the inhibitory level cannot be ruled out.

Dietary acetoacetate has been reported to lower the hepatic NAD level in rats $(16,17)$. In the present experiments, acetoacetate was hardly inhibitory to either intact mitochondrial or partially purified kynurenine 3-hydroxylase. The data in Table 4 suggest that substances, which inhibit kynurenine 3-hydroxylase from $S$. carlsbergensis, have a commonness of structure, that is, they are all $\alpha$-keto acids.

As a consequence of kynurenine 3-hydroxylase inhibition by $\mathrm{KIC}$, is kynurenine accumulated or is metabolism via kynureninase or kynurenine aminotransferase accelerated? Evidence for the direction in which metabolism of kynurenine is shifted is lacking at this moment. Leucine aminotransferase activity was reported to increase by giving animals leucine. In Saccharomyces, however, no such phenomenon was observed.

Whether similar inhibition by KIC is observed with mammalian kynurenine 3hydroxylase is an interesting problem and will be reported in the following paper.

\section{REFERENCES}

1) Shin, M., Sano, K., and Umezawa, C. (1981): Effect of L-tryptophan and L-leucine on biosynthesis of niacin related compounds in Saccharomyces carlsbergensis. J. Nutr. Sci. Vitaminol., 28, 179-189.

2) Bandlow, W. (1972): Membrane separation and biogenesis of the outer membrane of yeast mitochondria. Biochim. Biophys. Acta, 282, 105-122.

3) Okamoto, H., and Hayaishi, O. (1969): Solubilization and partial purification of kynurenine hydroxylase from mitochondrial outer membrane and its electron donors. Arch. Biochem. Biophys., 131, 603-608.

4) Wakabayashi, K. (1974): Preparation of yeast mitochondria. Protein, Nucleic Acid and Enzyme (in Japanese), 74, 349-357.

5) Kaneko, T., Kitamura, K., and Yamamoto, Y. (1973): Susceptibilities of yeasts to yeast cell wall lytic enzyme of Arthrobacter luteus. Agric. Biol. Chem., 37, 2295-2302.

6) Dubois, M., Gilles, K. A., Hamilton, J. K., Rebers, P. A., and Smith, F. (1956): Colorimetric method for determination of sugars and related substances. Anal. Chem., 28, 350-356.

7) Schott, H., Ullrich, V., and Staudinger, H. (1970): Enzyme properties of L-kynurenine 3-hydroxylase [EC 1.14.1.2] in Neurospora crassa. Hoppe-Seyler's Z. Physiol. Chem., 351, 99-101.

8) Lowry, O. H., Rosebrough, N. J., Farr, A. L., and Randall, R. J. (1951): Protein measurement with the folin phenol reagent. J. Biol. Chem., 193, 265-275.

9) Ichihara, A., and Koyama, E. (1966): Transaminase of branched chain amino acids. I. Branched chain amino acid- $\alpha$-ketoglutarate transaminase. J. Biochem., 59, 160-169.

10) Noda, C., and Ichihara, A. (1974): Control of ketogenesis from amino acids. II. Ketone bodies formation from $\alpha$-ketoisocaproate, the keto-analogue of leucine, by rat liver mitochondria. J. Biochem., 76, 1123-1130. 
11) Nisimoto, Y., Takeuchi, F., and Shibata, Y. (1975): Isolation of L-kynurenine 3hydroxylase from the mitochondrial outer membrane of rat liver. J. Biochem., 78, 573-581.

12) Ikeda, M., Tsuji, H., Nakamura, S., Ichiyama, A., Nishizuka, Y., and Hayaishi, O. (1965): Studies on the biosynthesis of nicotinamide adenine dinucleotide. II. A role of picolinic carboxylase in the biosynthesis of nicotinamide adenine dinucleotide from tryptophan in mammals. J. Biol. Chem., 240, 1395-1401.

13) Okamoto, H., Okada, F., and Hayaishi, O. (1971): Kynurenine metabolism in hyperthyroidism. A biochemical basis for the low NAD(P) level in hyperthyroid rat liver. J. Biol. Chem., 246, 7759-7763.

14) Wohlhueter, R. M., and Harper, A. E. (1970): Coinduction of rat liver branched chain $\alpha$-keto acid dehydrogenase activities. J. Biol. Chem., 245, 2391-2401.

15) Patel, T. B., Waymack, P. P., and Olson, M. S. (1980): The effect of the monocarboxylate translocator inhibitor, $\alpha$-cyanocinnamate, on the oxidation of branched chain $\alpha$ keto acids in rat liver. Arch. Biochem. Biophys., 201, 629-635.

16) Shastri, N. V., Nayudu, S. G., and Nath, M. C. (1967): Effect of acetoacetate and $\beta$ hydroxybutylate on the biosynthesis of niacin from tryptophan. J. Vitaminol., 13, $47-51$.

17) Shastri, N. V., and Nath, M. C. (1973): Effect of acetoacetate on liver and blood pyridine nucleotides in rats. J. Nutr. Sci. Vitaminol., 19, 349-353. 